\title{
Anti-essentialism, modal relativity, and alternative material-origin counterfactuals
}

\author{
Frederique Janssen-Lauret ${ }^{1}$ (D)
}

Received: 9 June 2020 / Accepted: 20 April 2021 / Published online: 28 April 2021

(c) The Author(s) 2021

\begin{abstract}
In ordinary language, in the medical sciences, and in the overlap between them, we frequently make claims which imply that we might have had different gametic origins from the ones we actually have. Such statements seem intuitively true and coherent. But they counterfactually ascribe different DNA to their referents and therefore contradict material-origin essentialism, which Kripke and his followers argue is intuitively obvious. In this paper I argue, using examples from ordinary language and from philosophy of medicine and bioethics, that statements which attribute alternative material origins to their referents are useful, common in political and medical reasoning, and in many cases best interpreted literally. So we must replace the doctrine of material-origin essentialism with one that can make sense of ordinary discourse and the language of the medical sciences. I propose an anti-essentialist account of such counterfactuals according to which individuals' modal properties are relative to a given inquiry.
\end{abstract}

Keywords Anti-essentialism · Modality · Essentialism · Essentiality of origins · Quine · Kripke

\section{Introduction: political and medical counterfactuals about alternative material origins}

When I ask people with an interest in American politics whether Hillary Clinton would have won the 2016 election if she had been a (cisgender) man, many of them answer 'yes', some, 'no', and some, 'it depends'. Proponents of 'yes' often mention sexism. Opponents may argue that after two consecutive terms of a Democratic president, a Republican victory was statistically likely. Some find it difficult to tell; two academics who staged a gender-swapped version of the 2016 presidential debate (Guadalupe and Salvatore 2017) found the audience response to the female Trump far more positive

Frederique Janssen-Lauret

frederique.janssen-lauret@manchester.ac.uk

1 Department of Philosophy, University of Manchester, Oxford Road, Manchester M13 9PL, UK 
than they had expected (Carrion 2017, pp. 9-10). But no one ever replies that the question makes no sense or is not about Hillary Clinton at all. Academics and ordinary English speakers alike treat questions about a female Donald Trump or a male Hillary Clinton as legitimate and answer them based on sound political reasons. A newspaper article on the gender-swapped debate experiment bore the title 'If Trump were a woman' (Jamieson 2017). In the political realm, we reason like this all the time.

Such reasoning flies in the face of Saul Kripke's thesis of the essentiality of material origins, which many analytic philosophers take to be intuitively obvious to both philosophers and ordinary-language speakers. It states that Hillary Clinton has the property of coming from the two particular gametes which produced her essentially. Material-origin essentialism implies that Clinton-a cisgender woman — could not have been a man, at least not a cisgender one. A cisgender man would be the product of a different pair of gametes from the ones that produced Hillary Clinton-in the simplest case, swapping one of her X-chromosomes for a Y-chromosome.

Material-origin essentialism is equally at odds with certain positions in the philosophy of medicine and bioethics. When someone has an illness or disability with a genetic cause which causes suffering with no benefits - as I do, for example-we ordinarily say that the person would have been better off without that illness or disability. Medical researchers, philosophers of medicine, and disabled people sometimes use such statements (first-personally or third-personally) to justify reproductive technologies which allow those traits to be selected out. I would have benefited from being free of a migraine-causing gene mutation, so I may rationally conclude in favour of genetic editing to eliminate it in my biological child, if available. Savulescu (2002) argues that a Deaf prospective mother might rationally choose to select for Deafness because she feels that it comes with more benefits than downsides. Although Savulescu's reasoning is third-personal, the Deaf prospective mother's conclusion is, like mine, inferred from a first-personal premise which flouts the essentiality of material origins: 'if I had not been Deaf, I would have lacked properties I value and want my child to share, such as fluency in sign language and being part of the Deaf community'.

My aim here is not to defend any moral or political positions, but one belonging to philosophical logic and philosophy of science: that reasoning and discourse like mine and the Deaf prospective mother's are logically coherent and possibly true. Many analytic philosophers are so steeped in material-origin essentialism that they rush to dismiss even serious, well-considered statements which attribute alternative material origins to their referents as confused, necessarily false or-if they are counterfactuals_-perhaps merely vacuously true.

A statement which varies the material origins of a referent, while holding some other range of the referent's characteristics (e.g. political, social, or psychological ones) fixed, I call an 'alternative material-origin' statement, or 'AMO' statement for short. They include AMO counterfactuals, such as 'if she had been male, she would have won' and AMO modal predications, e.g. 'she could have been male'. Ordinarylanguage speakers regularly use AMO statements, like the following counterfactuals,

1. 'I would have been better off without the gene mutation that causes my migraines.' (me) 
2. 'If you made Hillary a man, she would not be Bill Clinton. She would still be an entirely different person from him, albeit one who lacks personal experience of sexism'. (Harding 2016)

3. 'If she were a man, she would be finishing her second term and prepping for the Supreme Court by now.' (Savali 2016)

4. 'if Queen Victoria had been born a boy ... he was Queen Victoria with a Y chromosome.' (Ridley 2019)

Interpreted literally, the antecedents of (1)-(4) attribute alternative material origins to a person, while holding fixed political, social, psychological, and some genetic characteristics.

In this paper I argue that the literal interpretation of (1)-(4) above is the correct one. Some AMO statements express theoretically important, literal, non-vacuous truths. They thereby contradict material-origin essentialism. First I lay out Kripke's line on AMO statements in Sect. 2. He contends that they are either metaphorical or confused statements which refer to "epistemic "counterpart[s]" (Kripke 1971, p. 20) of their intended referents. I rebut Kripke's charges in Sects. 3 and 4. I provide additional context for the AMO counterfactuals above and argue, drawing on philosophy of medicine, philosophy of science, philosophical logic, and philosophy of language, that Kripke's reading of them yields highly implausible consequences. Instead I defend (Sects. 5-7) a literal, anti-essentialist reading of AMO statements like the above, appealing to what I call 'modal relativity'. According to modal relativity, an individual's modal characteristics are not fixed absolutely, by her essence or material origins, but vary relative to which features are made most salient by a given inquiry.

\section{Kripke on alternative material-origin counterfactuals}

Kripke and his followers maintain that material-origin essentialism faithfully reflects ordinary English usage and speaker's intuitions. Kripke finds certain properties easy to change in the imagination, like Queen Elizabeth's upbringing and ascension to the throne, but finds it 'harder to imagine ... her being born of different parents'. He then opines, 'It seems to me that anything coming from a different origin would not be this object' (Kripke 1980, p. 113). But the latter is not a logical consequence of the former; it is just an intuition of Kripke's. That it is harder to imagine her coming from different gametic origins does not entail that she could not have come from different gametic origins, nor that material-origin essentialism is 'the view of the man on the Clapham omnibus' (Hughes 2004, p. 84). Ordinary English speakers probably do find some characteristics easier to change in the imagination than others, but as we've seen, they definitely do not always speak in ways that uphold material-origin essentialism.

Kripke's official line is that anyone seriously venturing an AMO statement is confused. His argument features a table or lectern, but replacing 'table' or 'lectern' with 'person', and 'made of ice' with 'male' or 'born male', makes it applicable to our case.

'If someone protests regarding [Hillary Clinton] ... that [she] could have been [male], I would reply that what he really means is that $a$ [person] could have [thought and acted] just like this one, and have been placed in the same posi- 
tion as this one, and yet have been [male]. In short, I could have been in the same epistemological situation in relation to $a$ [male person] as I actually am in relation to this [person]. ... Here, then, the notion of 'counterpart' comes into its own. For it is not this [person], but an epistemic 'counterpart', wh[o] was [born male] ... Precisely because of this fact, it is not this [person] wh[o] could have been [male]. Statements about the modal properties of this [person] never refer to counterparts. However, if someone confuses the epistemological and the metaphysical problems, he will be well on the way to the counterpart theory' (Kripke 1971, p. 20, n. 15, his italics).

Kripke does not say, here or in Naming and Necessity, that AMO modal predications express necessary falsehoods. In this passage he says, rather, that AMO statements are confused insofar as they fail to refer to their intended referents, and refer instead to 'epistemic counterparts'. Although Kripke is not wholly explicit about what he means, and does not fully distinguish anti-essentialism (which I endorse) from counterpart theory (which I oppose), we can extract from the quotation three distinct charges of confusion against his opponent.

First, Kripke claims that his anti-essentialist opponent refers to the wrong object or person because she 'confuses the epistemological and the metaphysical problems'. The argument that all or some AMO statements express epistemic, not metaphysical, possibilities remains popular among philosophers of science and medicine (Maung 2020), many of whom repeat Kripke's charge that AMO statements rely on 'confusing' epistemic and metaphysical modality (Johnston 2011, p. 183; Korman 2005, p. 654; Walker 2008, p. 353). But Kripke's only motivation for his first charge of confusion is that he imagines his opponent reasoning, fallaciously, that the referent 'could after all have turned out to have [had different material origins], and therefore could have [had different material origins]' (Kripke 1971, p. 20, n. 15, his italics). As I'll argue below, anti-essentialists need not commit this fallacy. Another charge of confusion, separable from the first, is Kripke's claim that whoever tries to utter an AMO counterfactual about, say, Clinton, 'really means' a different claim about someone else, namely about her epistemic counterpart. 'Really means' is an ambiguous phrase, and yields two separate charges of confusion in turn when disambiguated. Both are independent of the first charge, because they are not premised on a fallacious inference from epistemic to metaphysical necessity. Kripke might mean that a speaker uttering an AMO counterfactual must 'mean it metaphorically' (Kripke 1971, p. 13). On this second charge of confusion, the speaker, perhaps inadvertently, makes a metaphorical claim instead of a literal claim of alternative material origins. Alternatively, Kripke might have in mind a third, distinct charge of confusion: that the speaker is confused because, while she really did intend to make a literal alternative material-origin statement, she fails to see that her statement, being one which ascribes alternative material origins, is defective. As a result she unintentionally utters a different statement, which is really about someone (or something) else: a true statement about an epistemic counterpart of the intended referent.

My real-life examples of alternative material-origin counterfactuals, uttered by ordinary English speakers, are not vulnerable to Kripke's charges of confusion when read in context. They are wholly coherent, in no way internally confused or contradictory. 
Once it has been established that AMO statements like (1)-(4) are coherent, we'll see in Sect. 5 that arguments for the essentialist claim that they must nevertheless be necessarily false, or merely vacuously true, either straightforwardly beg the question against the anti-essentialist or invoke principles which the anti-essentialist has good reason to deny.

\section{Philosophy of medicine and first-personal alternative material-origin counterfactuals}

As I suffer from painful migraines, I regularly have cause to judge that I would have been better off without them. My migraines are hereditary ones caused by mutations on four specific genes. Knowing this, I might, seemingly rationally, wish that my genome had not included the migraine-causing mutations. Suppose that reproductive technology to select out the migraine-causing mutations, perhaps via gene-editing or pre-conception genetic selection, becomes available for my future biological child. I then, again seemingly rationally, use the premise that I personally would have benefited from being free of the mutation to derive the conclusion that my child will benefit from being free of it. But material-origin essentialists in bioethics and the philosophy of medicine contend that I cannot rationally claim, even counterfactually, that I would have benefited from such minor changes to my genes. A human being with DNA exactly like mine except for the absence of migraine-inducing gene mutations, they say, would have slightly different material origins, and would therefore not be me. My first-personal AMO statement-(1) above-is a strong test case for the logical coherence of claims about harm or benefit that comes to a person by dint of minor changes to her DNA. I argue that (1) is as true as it sounds, that it does not succumb to Kripke's charges of confusion, and that it gives rise to a Humphrey objection against Kripke. For first-personal cases like mine, it is Kripke's approach to AMO statements which appears confused.

The point I formulated in terms of counterfactual benefit to an existing human being, first-personally, is more commonly put in terms of the coherence of discourse about harm to future people not yet conceived, third-personally (Gardner 2016; Heyd 2009; Smajdor 2014; Walker 2008; Williams and Harris 2014; Wrigley 2012). A key problem in the literature on the third-personal problem is the incompatibility between materialorigin essentialism and any claim that a human being is harmed by having the DNA she actually has. (As an anti-essentialist, I deny that any person is necessarily identical to some human being. So I use 'human being' where the bioethics literature uses 'person', though nothing in the argument that follows hangs on this.) To suppose that she would have benefited from having different DNA is to ascribe alternative material origins to her counterfactually. As a result, material-origin essentialists claim, the supposition is not about her, but about someone else. While some bioethicists offer counterparttheoretic solutions (Williams 2013; Wrigley 2012), others cling to material-origin essentialism and seek to refine the harm claims (Gardner 2016; Smajdor 2014; Walker 2008).

Some note that material-origin essentialism itself stands in need of refinement, too. As we saw above, Kripke speaks of 'different parents' as equivalent to 'a different 
origin' (Kripke 1980, p. 113), but developments in reproductive technology such as three-parent embryos (Schaefer and Labude 2017) imply that different parentage is compatible with identity of gametic origins. Wrigley distinguishes 'genetic' from 'gametic' origin essentialism, and ascribes the gametic version to (Kripke 2012, p. 177 n.5). A minority of self-identifying Kripkeans embrace a weak gametic essentialism which allows for minor changes to the genotype. Burgess, for example, claims that 'Aristotle might have had hemophilia [in case of] a cosmic ray striking the egg and causing a mutation on its X-chromosome' (Burgess 2013, p. 60). Several bioethicists and philosophers of medicine explicitly embrace a strict gametic essentialism. They take the material origins of a human being to be some particular 'sperm and egg' (Smajdor 2014, p. 333; Gardner 2016, p. 325). But Cooper (2015, pp. 500-501) poses a dilemma for gametic essentialists. Either gametes have material origins in turn, namely physical particles, which implies that she would have been a different human being if her father had eaten different food prior to producing the relevant gametes. Or gametic essentialism collapses into genetic essentialism, where the importance of genes is in coding for observable phenotypic traits. This amounts to valuing the genotype only for its phenotypic effects, which Cooper finds implausible. I note that it also sits uncomfortably with Kripke's statement, 'I might have been deformed if the fertilized egg from which I resulted had been damaged' (1980, p. 115, n. 57), since in that case the genotype is preserved, but the phenotype substantially altered. These difficulties are thorny. But I will set them aside. Even if Kripke can answer all these objections, his case collapses if the point is put first-personally.

Take (1) above, 'I would have been better off without the gene mutation that causes my migraines.' My statement is true and, I argue, literally true, and true of me, or at least of me qua human being or of my body. Kripke's first charge (Sect. 2 above) says that someone who utters an AMO statement 'confuses' (Kripke 1971, p. 20, n. 15) epistemic and metaphysical modality. This approach is hopeless when it comes to first-personal AMO statements about illness or disability. Kripke only entertains AMO statements fallaciously inferred from a statement of epistemic possibility. He imagines his opponent reasoning that the referent 'could after all have turned out to have [had different material origins], and therefore could have [had different material origins]' (Kripke 1971, p. 20, n. 15, his italics). But when I say of myself that I would have been better off without the migraine-causing gene mutation, it is absurd to suppose that I must have reached this conclusion by thinking, 'for all I know I could turn out to be without the migraine-causing gene mutation, and therefore I could have been without it'. My judging that I would have been better off without hereditary migraines certainly does not stem from my being confused or unsure about whether I actually suffer from them or not. It is precisely because they cause me suffering that I know I would have been better off without them.

Kripke's second charge, that my statement is 'metaphorical', looks no more promising. Even an apt metaphor is literally false. But all of the words concatenated in my statement have their ordinary, literal meanings, and I meant it literally. So I deny Kripke's claim that my statement is literally false. It is straightforwardly, literally true.

Kripke's third charge states that by first-personally wishing myself free of a migraine-causing gene mutation, I 'really mean[t]' a statement about someone else altogether, my epistemic counterpart. Here my objection to Kripke resembles Kripke's 
own famous line about Humphrey. Kripke rebutted counterpart theory, arguing that it misrepresents Humphrey's first-personal interest in electoral victory. 'Humphrey could not care less whether someone else, no matter how much resembling him, would have been victorious in another possible world' (Kripke 1980, p. 45, n. 13). Material-origin essentialism similarly misrepresents my first-personal thought. I was not wishing my epistemic counterpart free of painful migraines, but myself. My thought was firstpersonal, and was therefore either true of me, or false. I take it to be true. So I referred to myself, assigning myself different genetic origins counterfactually.

\section{A closer look at real-life, third-personal examples of alternative material-origin counterfactuals}

Ascribing alternative material origins in the third person is no less coherent. Example (2) comes from an article by the feminist writer Kate Harding, in which she defends voting for Hillary Clinton rather than Bernie Sanders. ${ }^{1}$ Harding describes Clinton's political characteristics — calling her 'the most qualified candidate', well 'vetted', 'the best candidate on women's issues' with a strong 'handle on global and domestic affairs'-and her psychological characteristics as Harding sees them-calling Clinton 'brilliant', 'ambitious', 'as sincere as any politician' with 'a history of admitting mistakes and, where possible, correcting them' (Harding 2016). Harding then holds fixed these political and psychological traits while counterfactually ascribing a different sex and gender to Hillary Clinton,

'If Bernie were running against a Bill Clinton who hadn't already served two terms, I would probably vote for Bernie. Some will say this proves that if you made Hillary a man, I wouldn't vote for her. ... I would refer those so inclined back to my opening remarks about developing a deep understanding of sexism before you can discuss this election knowledgeably. If you made Hillary a man, she would not be Bill Clinton. She would still be an entirely different person from him (albeit one who lacks personal experience of sexism and the embodied experience of being a woman, which are among the many things I do find worth considering).' (Harding 2016)

Harding does not leave herself open to the first charge I extracted from Kripke's passage above, that she 'confuses the epistemological and the metaphysical' (Kripke 1971, p. 20, n. 15). She makes clear that she intends to make the metaphysical possibility claim that Hillary Clinton really could have been a cisgender man with alternative

\footnotetext{
1 An anonymous referee asks for examples of AMO counterfactuals from centrist and right-leaning sources. In addition to (4) above from the $T L S$-a supplement of the right-leaning Times - a sample includes the following, from the right-wing tabloid The Sun: 'if she had been born a boy, she would have "been a drag queen because I love all the flamboyant stuff"' (Wootton 2019); from the politically neutral BBC: "As two Dukes list their numerous titles, the daughter of another explains what her position would be had she been born a boy' (Anonymous 2015), and from the regional Eastern Daily Press: 'From her Norfolk farmhouse, Lady Glenconner can see Holkham estate's boundary wall-had she been born a boy, the 27,000 acre stately family pile would be hers' (Briggs 2019). The question whether AMO statements are more commonly made by left-wing and centrist speakers than by right-wing speakers is beyond the scope of this paper, but a potentially interesting empirical question in its own right.
} 
material origins, not the epistemic possibility claim that Clinton might actually have turned out to be a man. In isolation, 'If you made Hillary a man' might be read either metaphysically or epistemically. Although the epistemic reading is harder to hear, perhaps Hillary Clinton might have turned out to be a transgender man with Hillary Clinton's actual material origins. But Harding removes any ambiguity between metaphysical and epistemic possibility when she specifies that the male Hillary she is concerned with would 'lack personal experience of sexism'. A transgender man assigned female at birth and socialized as a girl before his transition would have relevant personal experience of sexism.

Leaving open the epistemic possibility that Clinton's sex or gender might actually be different from what we suppose it to be is nowise a necessary condition for discussing the metaphysical possibility of Clinton having a different sex or gender from the one she actually has. Harding is in no doubt that Clinton is cisgender and female. In the context in which she is writing - an accessible article about politics-outlandish sceptical scenarios can be safely ruled out. It is fair to say that Harding admits no epistemic possibility at all that Hillary Clinton is actually male. Still, she coherently attributes maleness to Clinton counterfactually.

Entertaining the metaphysical possibility of someone's having alternative material origins is not in the least inherently confused, and certainly does not entail mistaking epistemic for metaphysical possibility. This is apparent from the fact that no contradiction follows from concatenating the negation of an epistemic possibility claim with the corresponding claim of metaphysical possibility. A conjunction like 'Hillary Clinton could not actually turn out to be a cisgender man, but if she had been a cisgender man, she would now be president' concatenates the negation of the epistemic possibility claim 'Hillary Clinton might actually turn out to be a cisgender man' with a subjunctive conditional which ascribes the modal predicate 'could have been a cisgender man' to her, entirely coherently. It is in no way ambiguous, confused, or contradictory.

Nor is Harding's statement vulnerable to Kripke's second charge of confusion: it is not, in context, plausibly interpreted as metaphorical. Harding carefully thinks through the implications of a counterfactual scenario in which Hillary Clinton is male, holding fixed her political and psychological characteristics and conjoining them with a precisely worded counterfactual attribution of both the male gender and the male sex to Hillary. Harding then compares Bill Clinton to that possible male Hillary. Harding concludes that while she would not vote for Bill if a more left-wing alternative like Sanders were available, she would vote for a male Hillary. The fact that she can do this shows that her statement is not metaphorical. Metaphors cannot sustain this kind of detailed comparison of all the real political and psychological qualities the subject literally has in common with that to which is it compared metaphorically. Romeo would be hard-pressed to enumerate any qualities which Juliet literally shares with the sun other than being beautiful and being awe-inspiring - setting aside a handful of rather trivial qualities like being self-identical and being located in space-time. By contrast, Harding engages in a quite different, non-metaphorical comparison; her possible male Hillary and the actual female Hillary literally share all relevant psychological, social, and political qualities - specific ones like being pro-choice and researching issues in depth - all qualities, in short, except those which come with being female rather than (cis) male. All the words in Harding's alternative material-origin counterfactual 'If 
you made Hillary a man' appear to have their standard, literal meanings. The only possible exception is 'made', but Harding's case would be equally strong if she had used the completely literal 'If Hillary were a man' instead.

Even more obviously non-metaphorical are AMO counterfactuals (3), by American political writer Kristen West Savali, and (4), from a popular article by historian Jane Ridley. Savali writes,

'HRC [Hillary Rodham Clinton] has faced and continues to face extreme sexism.

The misogyny is palpable. If she were a man, she would be finishing her second term and prepping for the Supreme Court by now' (Savali 2016).

Like Harding, Savali keeps in place Clinton's political positions, expertise, experience, ambitions, qualifications, and mental characteristics, while counterfactually assigning her a different gender and (implied) biological sex and therefore alternative material origins. Savali (who is Black and more left-wing) thinks less highly of Clinton's political positions and character than Harding (who is white and more centre-left) given Clinton's hawkish foreign policy and her mixed record on racism and police brutality. Still, she and Harding agree that Clinton would have had an easier political career if she had been male. All of Savali's words in 'If she were a man' clearly and straightforwardly have their standard, literal meanings.

Ridley, like Harding above, engages in a detailed counterfactual comparison of a possible male Queen Victoria with the actual female Queen Victoria. Ridley's account includes explicit stipulations about her male Victoria's DNA, making an interpretation which assigns alternative material origins unavoidable. 'I will assume that ... he was Queen Victoria with a Y chromosome' (Ridley 2019). Like Harding, she carefully considers a metaphysically possible scenario in which Victoria has both the male gender and the male sex, while holding fixed Victoria's political, psychological, and most of her genetic characteristics, resulting in statements like: 'If Victoria had been a man ... the modernizing reforms of Prince Albert might not have taken place ... What would have happened if Prince Albert had not died in 1861 is a counterfactual question that historians often ask. One way to think about it is to imagine that Victoria was a man, and there was no break in the reign in 1861' (Ridley 2019). There is no possibility of a metaphorical interpretation here, or one which confuses metaphysical and epistemic modality.

The only charge of confusion Kripke has left to bring against Harding, Savali, and Ridley is the third one: that they, aiming to refer to Hillary Clinton or Queen Victoria, accidentally end up referring to some man who is Clinton's or Victoria's epistemic counterpart. Kripke's stated position is that neither Savali, nor Harding, nor Ridley knows 'what [s] he really means' (Kripke 1971, p. 20, n. 15) — that she does not manage to refer to Hillary Clinton or Queen Victoria at all, but unintentionally changes the subject to refer to someone completely different.

Anti-essentialists are perfectly entitled to maintain instead that Harding and Savali really do refer to Hillary Clinton, and Ridley to Victoria. All the signs point to those authors' engaging in careful, thoughtful reasoning about their intended referents. Kripke has provided no principled argument why reference should fail in (2)-(4) above other than his already decisively refuted claims that (2)-(4) are metaphorical or confuse epistemic and metaphysical necessity. I propose to read Harding, Savali, and Ridley 
literally. They describe possible counterfactual scenarios in which Hillary Clinton or Queen Victoria are male.

Above, I presented a first-personal Humphrey objection against Kripke's third charge of confusion: the person I wished free of painful migraines was not my epistemic counterpart, but me. Here I put forward a third-personal analogue. The original third-personal Humphrey objection says that possibly having won the 1968 election is a genuine modal property of Humphrey himself, not a non-modal property of someone else, a counterpart, no matter how much resembling Humphrey (Hughes 2004, pp. 128-129). Let us call my third-personal version 'the Humphrey-Clinton objection': possibly having won the 2016 election if male is a genuine modal property of Hillary Clinton herself, just as possibly having won the 1968 election is a genuine modal property of Humphrey. It is not a non-modal property of some man who is Clinton's epistemic counterpart. As we've seen, Harding and Savali's AMO counterfactuals regarding Clinton appear to attribute a genuine modal property to her, not at all to change the subject by talking about some man distinct from Hillary Clinton. Harding and Savali want to express important truths about this very person's, Hillary Clinton's, role with respect to the intersection of politics and sexism and, in Savali's case, also the political interplay between gender and race. They say that this very person's modal properties in the political realm change in significant ways when we assign her alternative material origins counterfactually.

Anti-essentialists who (like me) are not counterpart theorists have a uniform story to tell about Clinton and Humphrey. He has the genuine modal property of possibly having won the 1968 election; she has the genuine modal property of possibly having won the 2016 election if male. Neither is analysed in terms of counterpart theory. By contrast, Kripke generally favours the 'genuine modal property of the referent' analysis for modal predications and counterfactuals, but makes an ad hoc exception for statements which ascribe alternative material origins. In the AMO case, he reaches for counterpart theory. But the question then arises: why? Ordinary-language speakers, as we have seen, do not routinely treat AMO statements differently. And we have seen that Kripke's official, published line, according to which AMO statements should be interpreted counterpart-theoretically because they are confused or fallacious, has not stood up to scrutiny. So the burden of proof is on material-origin essentialists to ward off the Humphrey-Clinton objection by producing a principled argument for their disjunctive treatment of AMO statements and others. Such a principled argument cannot simply consist in the assertion that material-origin essentialism is true, as that is just what anti-essentialists see good reason to deny. ${ }^{2}$

\footnotetext{
2 An anonymous referee suggests an alternative account on behalf of the essentialist: that AMO counterfactuals be analysed along similar lines to the analysis of 'counter-mathematicals' of Baron et al. (2020), Jenny (2018). According to these accounts, certain mathematical counterfactuals with necessarily false antecedents can be interpreted as literally, non-trivially true if they are taken to describe impossible worlds. I reply that, first of all, positing impossible worlds carries heavy ontological and interpretive costs (Williamson 2007, ch. 5). So an ontologically parsimonious interpretation without impossible worlds is prima facie preferable to one which posits them. Second, impossible-world-based interpretations constitute just as disjunctive a treatment of AMO statements vs. other statements as Kripke's. On the referee's proposed account, AMO statements would be interpreted as describing impossible worlds even if they sound plausible to ordinarylanguage speakers, while non-AMO statements which appear plausible would be interpreted as describing possible worlds. But the anti-essentialist has a smoother, uniform story. According to her, both plausible-
} 


\section{Rebutting arguments for material-origin essentialism}

One common line of argument states that philosophers are entitled to take metaphysical theses like material-origin essentialism as true based on intuitions. The intuition-driven essentialist concedes that AMO counterfactuals are coherent, not confused, but declares that they are different from other counterfactuals because her metaphysical intuition tells her that their antecedents are necessarily false, since the referent necessarily lacks the alternative material origins ascribed by the AMO statement. As a result, she concludes, AMO counterfactuals are at best merely vacuously true. Intuition-based essentialism is common in the philosophy of science literature-'scientific essentialism [is] the thesis that there are metaphysically necessary truths which can be known only a posteriori. The most frequently cited arguments for this position rely on modal intuitions' (Korman 2005, p. 650)_including the philosophy of medicine literature on which I focus here: 'adherents of the doctrine of the necessity of origins adopt the position because they find it intuitively plausible (Cooper 2015, p. 499). Some baldly state, without citing Kripke or other essentialist literature, that it is true, or intuitive, that a particular human being must have come from a given 'sperm and egg' (Smajdor 2014, p. 333; Gardner 2016, p. 325). This does nothing to convince the antiessentialist. That certain counterfactual statements which contradict the essentiality of material origins are possibly, non-vacuously true is precisely what the anti-essentialist believes and finds intuitive.

Material-origin essentialists who feel entitled to consider metaphysical theses true based on intuitions must grant that the anti-essentialist is equally entitled to consider them false based on her own, opposing intuitions. While I place less methodological weight on intuitions than Kripke, how things seem to me is very different from the way they seem to him. It seems to me (as it did to Locke) easy to imagine a person coming from different material origins, if her psychological characteristics are preserved. Anti-essentialists in philosophy of medicine and bio-ethics also assert ethical intuitions at odds with material-origin essentialism. Heyd (2009) points out that material-origin essentialism is in tension with the justification of reparations for historical injustices like slavery, because people with the exact DNA and parentage of those to whom reparations would be paid probably would not have existed without the historic injustice. The normatively intuitive force of the case for reparations can outweigh, or make us re-evaluate, any intuitive appeal of material-origin essentialism. Williams and Harris (2014) assert the ethical intuition that it is possible for parents to harm a child if they deliberately conceive that child while knowing that it will have a specific genetically-based disability. Gametic essentialists are forced to deny that

Footnote 2 continued

sounding АMO statements and plausible-sounding non-AMO statements describe possible scenarios. To insist that impossible worlds are needed to interpret AMO counterfactuals is effectively to assume that essentialism is true. After all, Jenny and Baron et al. feel the need to posit impossible worlds only because they maintain that the antecedents of counter-mathematicals are themselves impossible-that is, necessarily false. But anti-essentialists who venture AMO counterfactuals like (1)-(4) above do so precisely because they take them to present genuinely possible scenarios in which, for example, Victoria is male. Anti-essentialism is therefore preferable to an approach modelled on Baron et al. or Jenny's, both because of its uniform treatment of AMO counterfactuals and others and its ontological parsimony. 
moral intuition because of their conviction that that child, being the essential product of a particular sperm and egg, could not have existed without that disability.

Gametic essentialists' attempts to dispel such anti-essentialist intuitions are illustrative because their arguments turn out simply to consist in reaffirmations of material-origin essentialism. When Williams and Harris say, of woman undergoing treatment for syphilis, 'should the woman choose to conceive now, she will conceive a child who suffers from the effects of congenital syphilis, and thus, her child will be born harmed by her action' (2014, p. 347), Smajdor replies that, 'If she waits, a different child will be born (free of syphilis) because a different egg and sperm will be involved ... The child conceived now could not exist without suffering from congenital syphilis. Therefore, it cannot be harmed by being brought into existence suffering from syphilis' (Smajdor 2014, p. 325, her italics; see also Gardner 2016, pp. 328-329 for an almost identical argument). Such reasoning does not constitute a defence of material-origin essentialism or even an explication of its intuitive appeal. It merely reiterates the essentialist credo-'a different child will be born because a different egg and sperm will be involved' - with added italics. But the anti-essentialist's belief is precisely that some statements which counterfactually ascribe alternative gametic origins to their referents are indeed literally true and theoretically important. As arguments for the necessary falsehood of AMO modal predications, or for treating AMO and non-AMO statements differently, reaffirmations of gametic essentialism are plainly question-begging. The anti-essentialist will not be swayed by them.

Other essentialists draw on passages from the main text of Kripke's Naming and Necessity where, they say, 'he introduces those [essentialist] principles by saying that they are suggested by reflection on particular examples' (Hughes 2004, p. 110). Kripke's examples in no way entail the necessary truth of material-origin essentialism, and their power to 'suggest' it is more limited than it appears at first sight. They involve imagining 'pointing to Nixon' (Kripke 1980, p. 41), or using italics in conjunction with what I will argue amount to biological descriptors of the body, such as 'this man' (Kripke 1980, p. 41), 'this very woman' (Kripke 1980, p. 113), and 'given the woman' (Kripke 1980, p. 113). No amount of pointing or saying 'this woman' in italics makes essentialism mandatory. After all, the result of concatenating such an expression with an AMO modal predicate is never self-contradictory. Imagine someone introducing speakers at a political rally. She points to Hillary Clinton and says: 'This woman would now be President if she had been born male.' Given the pointing and the utterance of 'this woman', it appears a paradigm case of a Kripke-style example which Hughes contends would, if not entail, then at least 'suggest' essentialist principles. But the speaker concatenates it with an AMO counterfactual, entirely coherently.

Why, then, does the impression persist that Kripke's examples make material-origin essentialism plausible? I conjecture that it is because they subtly prime the reader towards foregrounding the physical body. Take his example about Elizabeth II.

'One can imagine, given the woman, that various things in her life could have changed... it's possible that even though she were born of these parents she never became queen ... But what is harder to imagine is her being born of different parents. It seems to me that anything coming from a different origin would not be this object' (Kripke 1980, p. 113, his italics). 
Kripke's phrasing — an italicised 'given the woman' — provides the impression of singling out the referent directly, non-descriptively. But his use of the term 'woman' belies that impression; in the sense in which Kripke uses it here, it appears to be a descriptor of the biological organism. 'Woman' in ordinary English has both a biological use, meaning roughly 'adult female human being', and a gendered use, which connotes socialisation, gender expression, or gender identity. Kripke's 'woman' above seems to have the biological sense. Replace it with 'female-gendered person', and the inference that it is difficult to imagine her being born of different parents appears shaky. Using 'person' creates room for the Lockean, for example, to affirm the contrary intuition that it is easy to do so, but difficult or impossible to imagine her having different psychological characteristics. (Locke indeed used 'man' for the biological organism, and 'person' for the psychological entity.)

For related reasons, there is little room for a third type of argument to get off the ground, namely a version of Kripke's 'something like proof' of material-origin essentialism (1980, p. 114, n. 56). Kripke assumes that we have names of an actual table ('B'), the hunk of matter which is its actual material origin ('A') and some other wholly distinct hunk (' $\mathrm{C}$ '). He then imagines a possibility where B is made from $\mathrm{A}$ and a distinct table $\mathrm{D}$ is made from $\mathrm{C}$. Kripke argues that because in that possibility, B is distinct from $\mathrm{D}, \mathrm{D}$ could not be $\mathrm{B}$ even if only $\mathrm{D}$ were made and no table were made from A. He concludes that B could not have been made from $\mathrm{C}$. Kripke's own version is clearly flawed. One familiar objection is that Kripke does not defend the principle which the essentiality of origins would require: that any table made from C, in any possible scenario, cannot be B (Salmon 1979, p. 709). Attempts to reconstruct an improved Kripkean proof emerged in response (see Forbes 1985, pp. 138-145 for a biological version and Rohrbaugh and deRosset 2004 for a general one). But several recent papers argue that the project is doomed (Robertson 1998; Cameron 2005; Damnjanovic 2010). These papers show that all reconstructions of Kripke's 'something like a proof' suffer from a common defect: they over-generalize significantly. They entail that objects have not just their material origins, but also apparently contingent features related to their material origins, like their place of origin and their spatiotemporal location, essentially. Another major underlying problem is that Kripke is not entitled to the premise that we have directly referential names, names which are not disguised descriptions, for alleged material origins like hunks of matter and gametes (MacBride and Janssen-Lauret 2015, pp. 297-299). Perhaps we have a directly referential name for Queen Elizabeth herself. ${ }^{3}$ But it is implausible to suppose that we refer directly to the gametes from which she originated over ninety years ago. Gametes, being theoretical posits of which are aware only against the backdrop of biological theory, are referred to by theoretical terms. And theoretical terms are best interpreted, in the Ramsey-Carnap-Lewis tradition, not as names (MacBride and Janssen-Lauret 2015, p. 298) or reference-fixing descriptions (Strevens 2012), but as expressions which capture a theoretical role descriptively (Andreas 2010; JanssenLauret and MacBride 2020a, b).

\footnotetext{
3 See Janssen-Lauret (2016), pp. 594-599 for an argument that if we do have directly referential proper names, they are not equivalent to definite descriptions.
} 
Burgess's tentative suggestion that statements of material-origin essentialism are 'analytic, ultimately resting on rules of language' (Burgess 2013: pp. 77) might amount to a fourth argument in favour of essentialism. But his suggestion sits awkwardly with ordinary-language examples of AMO statements like (1)-(4) above, and with the example used in this section, 'This woman would now be President if she had been born male'. All are perfectly congruent with the rules of English.

\section{Anti-essentialism and modal relativity}

Anti-essentialism does not entail that traits like gender, race, or disability are nonessential in the sense of being unimportant, or easily changed. My account is compatible with positions on gender, race, or disability on which they are permanent characteristics. My proposal does not imply that my migraine-causing gene mutation can actually be rectified. But the causal impossibility of presently changing my DNA does not imply that I cannot counterfactually be described as possibly having different DNA. An AMO counterfactual about someone's sex, gender, race, or disability can be literally true even if that person actually lacks the power to change their sex, gender, race, or disability in the way the counterfactual describes. Counterfactuals are subjunctive, contrary-to-fact conditionals. There need not be anything actual that exhibits the pattern they describe for them to be true. By way of illustration, consider the nonpolitical counterfactual 'If humanity had had its origins on the Moon, we would find it difficult to get used to the Earth's gravity'. It is an AMO counterfactual, because humanity's actual material origins were on Earth. It seems true. Since the Moon's gravity is much less than the Earth's, things are much lighter there than here. There is no need to pronounce it false because we did not actually originate on the Moon and cannot cause ourselves to be.

My anti-essentialism does not say that 'the notion of a necessary or contingent property ... is a philosopher's notion with no intuitive content' (Kripke 1980, pp. 4142). Kripke writes, 'When you ask whether it is necessary or contingent that Nixon won the election, you are asking the intuitive question whether in some counterfactual situation, this man would in fact have lost the election' (Kripke 1980, p. 41). He takes himself thereby to have refuted the view that 'whether an object has the same property in all possible worlds depends not just on the object itself, but on how it is described' (Kripke 1980, p. 41). But he has not. His Nixon argument is not effective against my anti-essentialism, the modal relativity variety.

Modal relativity grants that there is some intuitive content to the essential-accidental boundary. Everyday discourse does not suggest an anarchic anti-essentialism where any characteristic can be counterfactually varied as easily as any other. Ordinarylanguage speakers intuitively treat certain features-such as being human or being rational - as more permanent and stable, more like essential properties, and othersperhaps winning an election, living in New York, having short hair-as easier to change or to imagine changing, more accidental. But we cannot conclude that the essential-accidental boundary is therefore absolute.

Certain questions and ways of presenting a referent foreground material characteristics-like Kripke's use of 'this woman' in the biological sense of 'woman', 
to present Queen Elizabeth II-leading us to think of those material traits as fixed, and of her political, social, or psychological characteristics as variable. But material origins need not be privileged no matter what. Other legitimate kinds of questions or statements, such as political ones, instead foreground individuals' other attributes — political, social, psychological—allowing us instead to think of their material characteristics as variable. Kripke's (hypothetical) ordinary-language speaker says that while "the actual winner might have been the loser ... "Nixon" is just a name of this man' (Kripke 1980, p. 41), suggesting that ordinary-language speakers draw an accidental-essential distinction this way. Ordinary English speakers do tend to take winning an election as accidental. It is less clear what Kripke's hypothetical speaker regards as the essential property here: being a man in the 'adult male human being' sense, being this man specifically, being this person, or being Nixon? Being chromosomally male requires certain biological origins. But, I argue, being this person, or being Nixon, does not. A political question such as 'would Nixon have won if he had been a woman?' is, to many competent English speakers, no less intuitive than the one Kripke poses. Such questions invite us to hold fixed relevant political, social, or psychological characteristics while treating biological sex as variable. An individual's modal properties are relative to a given inquiry, not fixed absolutely.

Anti-essentialism is not the only possible interpretation of the kinds of AMO counterfactuals in ordinary language I discuss above. An alternative reading is psychological essentialism, according to which people cannot lose their psychological characteristics and remain the same person, even though the same psychological characteristics may co-exist with different material origins. Psychological essentialism may be the view of some philosophers, or congenial to certain kinds of ordinarylanguage discourse. But everyday English also contains counterfactuals which vary the material origins of objects without psychological states, foregrounding their aesthetic, historical, or social characteristics. Take Kripke's lectern: 'If someone protests, regarding the lectern, that it ... could have been made of ice, I would reply that what he really means is that a lectern could have looked just like this one, and have been placed in the same position as this one, and yet have been made of ice' (1971, p. 20, n. 15; his italics). Suppose the lectern Kripke discussed is made of pine, has some historic value, and has just been acquired by a local museum. The curator laments: 'I wish this lectern had been made of hardwood instead. If it had been, it would have been in a better condition than it actually is'. Her colleague jokes, 'At least it wasn't made of ice. It would have been in a much worse condition then, because it would have melted'. Unlike psychological essentialism, anti-essentialism can account for such cases.

\section{A Quine-inspired perspective on AMO counterfactuals}

Asking à propos of nothing whether Nixon could have been a woman, or born in the 18th century, might earn you a quizzical stare, or some hesitant reflections on transgender identity or a time-travelling mother. But when you ask whether Nixon would have been elected if he had been a woman, or would have made a success of the Revolutionary War if he had been in charge, your interlocutor will know how to use relevant anti-essentialist assumptions as a basis for reasoning. We straightforwardly 
'feign belief in the antecedent and see if the consequent follows' (Quine 1960, p. 222) including in cases where the antecedent contains an AMO modal predication. But we may feign belief in the antecedent in a variety of ways, privileging different aspects of the descriptions we hold true. Compare:

'If Boadicea had been Prime Minister of the United Kingdom, she would have made Boris Johnson obey her.'

'If Boadicea had been Prime Minister of the United Kingdom, Boris Johnson would have had no idea what she was telling him to do in Old Brittonic.'

Someone who asserts the first counterfactual holds fixed Boadicea's political acumen and courage, but counterfactually assigns her different material origins by transplanting her to the twenty-first century. Someone who asserts the second also holds fixed the languages Boadicea spoke. Either could plausibly be considered true-Boadicea was a fearsome leader; Boadicea's native language was Old Brittonic_-but they are not compatible. (Hegelians might suggest a synthesis where Boadicea instructs Boris, who has a classics degree, in Latin.)

Quine's page-and-a-half on counterfactuals in Word \& Object was part of what inspired his student Lewis's account (Lewis 1973: 66-67). Lewis appeals to concrete possible worlds, ranked by similarity in relevant respects to the actual world, and pronounces a counterfactual true just in case in all of the closest possible worlds where its antecedent is true, its consequent is also true. Its antecedent is true in those worlds where the referent's counterpart(s), the entity or entities most similar to it in that world, satisfies or satisfy its predicate, and likewise for the consequent. Lewis's analysis of counterfactuals is rigorous and worked out in painstaking detail. Nevertheless, an account of AMO counterfactuals inspired by Quine's remarks is clearly preferable.

Lewis's counterpart-theoretic version is ontologically extravagant. It presupposes an infinite array of concrete possible worlds, each with its own space-time. Worse, Lewis's view is vulnerable to both the Humphrey objections I pressed against Kripke. When I say that I would have been better off without my migraine-causing gene mutation, I argued above, my statement is first-personal. It is either true of me, or false. It is not true of my epistemic counterpart instead of me, as Kripke would have it, nor of the person most resembling me in some faraway concrete possible world, as Lewis would say. When Savali says of Clinton, 'If she were a man, she would be finishing her second term [as US president]' (Savali 2016), she is attributing to Hillary Clinton herself the genuine modal property of possibly having been elected president if male. She is not attributing the non-modal property of being a male president to some denizen of some parallel island universe, no matter how much he resembles Clinton. All of Lewis's counterfactuals are made true by counterparts. This gives him the advantage over Kripke in being able to tell a consistent story about AMO statements and others. But it leaves him open not just to Kripke's Humphrey objection, but also to the first-personal and Humphrey-Clinton versions of the objection which I presented above. Lewis might reply that to care about my counterpart is to care about me, that the truth that I would be free of migraines with different genes is accounted for by my happier counterpart who does have different genes (Lewis 1986, pp. 196-197). I am not convinced. While I might grant that in a looser sense of 'about', statements about my counterparts are about me, when I wish myself free of painful migraines what I 
wish is for my own pain to stop, or for that pain never to have existed. I want it to be true of me, the actual me, that I do not suffer from painful migraines. The desire to relieve my own pain is self-directed in a way which differs from care about others. My counterparts are others, and not me, insofar as I do not feel their physical pain and they do not feel mine. My anti-essentialism will not draw on counterpart theory.

I propose to explicate what I described as holding fixed certain characteristics $\phi$ and $\chi$ of an individual $x$ and varying another, $\psi$, as redrawing our description of that individual, substituting other predicates for those which express $\psi$, and keeping the predicates expressing $\phi$ and $\chi$ in place. Where the counterfactual is a scientific one about a specific posit, our descriptions will be detailed, descriptive theoretical terms. ${ }^{4}$ The truth-conditions of such counterfactuals are a resultant of the descriptions and generalizations the relevant science allows. Quine hints at such a view when he says, 'the respectable vestige of essentialism [which] consists in picking out those minimum distinctive traits of a chemical, or a species, or whatever, that link it most directly to the central laws of the science [is] of a piece rather with the chemical or biological theory itself' (Quine (1976) [1972], p. 52).

Take Ridley's AMO statement (4) above, about a cisgender male 'Queen Victoria with a Y-chromosome'. In the biological realm, there is an obvious way to interpret such statements, namely to take a full theoretical description of Victoria, focus on the predicates which describe her DNA, and replace the description of one of her $\mathrm{X}$-chromosomes with one of a Y-chromosome. On this basis biologists will be able to assess a counterfactual like 'if she had been male, Queen Victoria would have had haemophilia' with a high degree of accuracy. The same is true of statements like, 'Without the mutation on their ATP1A2 gene, this person would not suffer from migraines' (cf. Roth et al. 2018).

AMO counterfactuals in the biological, chemical, and physical sciences will contain theoretical terms which capture a theoretical role descriptively. The roles delineated by a theory concern a place in a structural system of relations which the fillers of that role have to the other posits of that theory. As I mentioned in Sect. 5, a theoretical term like 'gamete' does not function like a directly referential name without descriptive content (MacBride and Janssen-Lauret 2015, pp. 297-299). Gametes cannot usually be ostended. They are not visible to the naked eye. We cannot do as Kripke suggests we do for gold or water, pointing and saying, "by "gamete" I mean something with the nature of this'. Further descriptions are needed to disambiguate whether we mean this very collection of molecules, or this bearer of genetic information encoding phenotypic traits. Nor can theoretical terms even function like reference-fixing descriptions. If someone says that by "gamete" she means that which codes for a given phenotype, her claim implies that it is analytic that either there are no gametes or they encode a given phenotype-but there are good reasons to oppose such analytic truths in science (Strevens 2012). Worse, Cooper (2015) and I (Sect. 3 above) argued that genetic essentialism which values genes only for their phenotypic effects is both implausible and

\footnotetext{
4 An anonymous referee asks whether this is a conventionalist view. I do not subscribe to conventionalism because I am not convinced either that there is a robust analytic-synthetic distinction or that logical and mathematical truths are true in virtue of language alone. I do think that a conventionalist who is also anti-essentialist could use my approach, which appears to be confirmed by Sidelle, a conventionalist who embraces essentialism, noting that anti-essentialism is a defensible alternative (Sidelle 2010, p. 112).
} 
at odds with Kripke's text. So biological, chemical, and physical counterfactuals will feature theoretical terms interpreted the Ramsey-Carnap-Lewis way. On this interpretation, a statement featuring a theoretical term does not express a singular claim about a posit; it comes with a measure of ontological relativity (Janssen-Lauret and MacBride 2020a,b). But compared to Kripke's approach to natural kind terms, mine has the advantage of yielding fairly determinate and regimented ways of both, as Quine put it, 'feigning belief in the antecedent' of an AMO counterfactual and 'see[ing] if the consequent follows'. For example, we regiment 'if Victoria were male' as a description of a human genome exactly like Victoria's except for the presence of a Y- instead of one $\mathrm{X}$-chromosome, and apply known biological laws about how the recessive $\mathrm{X}$-linked disorder haemophilia is inherited.

Generalizations belonging to the social sciences often involve more complex patterns and more unknown factors than cases from the natural sciences. Which aspects of a theoretical description to hold fixed and which to vary may be less clear as a result. Questions about, for example, whether Hillary Clinton would now be president if she were male involve more disagreement even among experts. Many well-informed political scientists are convinced the answer is 'Yes'. But others cite, for example, statistical patterns indicating that a swing towards the Republicans was likely. In addition, theoretical statements in the social sciences may in some cases be firstpersonal as well as third-personal. Unlike third-personal theoretical statements given a Ramsey-Carnap-Lewis reading, first-personal theoretical statements contain terms which are not reducible to descriptions, and do express singular claims about the thinker or speaker herself (Janssen-Lauret 2018). In the social sciences, and in ordinary language, I do not rule out that Ruth Barcan Marcus (Barcan Marcus 1961, pp. 309-310) or Kripke may prove correct that there are directly referential expressions whose meanings are just their bearers. Direct reference is perfectly compatible with anti-essentialism. Barcan Marcus herself made clear that the only properties which an object $a$ provably has necessarily are the logical properties, such as self-identity and not satisfying contradictory predicates, plus being identical to $a$ (Barcan Marcus 1967).

When we judge counterfactuals in everyday discourse, we similarly hold fixed and vary predicate ascriptions, but we do so in a way which is less systematic than the scientific cases. We implicitly consider what we know about the referent-descriptions as well as perhaps directly referential, practical, or perceptual knowledge-imagine some of it being different, and think about what follows from those assumptions. Consequently, natural-language counterfactuals might allow for filling in missing information in a wide variety of ways. In the Boadicea case above, the interpretation shifts if we assume a historic versus a modernized Boadicea. The general recipe for interpreting counterfactuals is the same for AMO ones, where material origins are varied in thought and other traits kept in place, as for those which hold material origins fixed.

Acknowledgements Thanks to Fraser MacBride, Hane Maung, Chris Daly, Lucija Duda, Simona Giordano, Ajinkya Deshmukh, Leonie Smith, Jane Heal, Emily Caddick Bourne, Helen Beebee, Veronique Pin-Fat, Neema Begum, three anonymous referees, and audiences at the University of Durham, the University of Manchester, the Manchester Centre for Social Ethics and Policy, and the Arché Research Group in Logic and Metaphysics at the University of St Andrews. 
Open Access This article is licensed under a Creative Commons Attribution 4.0 International License, which permits use, sharing, adaptation, distribution and reproduction in any medium or format, as long as you give appropriate credit to the original author(s) and the source, provide a link to the Creative Commons licence, and indicate if changes were made. The images or other third party material in this article are included in the article's Creative Commons licence, unless indicated otherwise in a credit line to the material. If material is not included in the article's Creative Commons licence and your intended use is not permitted by statutory regulation or exceeds the permitted use, you will need to obtain permission directly from the copyright holder. To view a copy of this licence, visit http://creativecommons.org/licenses/by/4.0/.

\section{References}

Andreas, H. (2010). New account of empirical claims in structuralism. Synthese, 176, 311-332.

Anonymous. (2015). If I had been born a boy. BBC. https://www.bbc.co.uk/programmes/p035nks0.

Barcan Marcus, R. (1961). Modalities and intensional languages. Synthese, 13, 303-322.

Barcan Marcus, R. (1967). Essentialism in modal logic. Noûs, 1, 91-96.

Baron, S., Colyvan, M., \& Ripley, D. (2020). A counterfactual approach to explanation in mathematics. Philosophia Mathematica, 2, 1-34.

Briggs, S. (2019). Norfolk's Lady Glenconner on success of her memoir and why The Crown has it wrong about Princess Margaret. Eastern Daily Press, https://www.edp24.co.uk/lifestyle/lady-glenconnermemoir-norfolk-princess-margaret-holkham-hall-assembly-house- 1462426.

Burgess, J. (2013). Kripke. Cambridge: Polity.

Cameron, R. P. (2005). A note on Kripke's footnote 56 argument for the essentiality of origin. Ratio, 18, 262-275.

Carrion, E. (2017). Does swapping the race and gender of communicators affect perspectives on leadership and securitization? Master's Thesis, University of Gothenburg, http://hdl.handle.net/2077/54155.

Cooper, R. (2015). How might I have been? Metaphilosophy, 46, 495-514.

Damnjanovic, N. (2010). No route to material origin essentialism? Erkenntnis, 72, 93-110.

Forbes, G. (1985). The metaphysics of modality. Oxford: Oxford University Press.

Gardner, M. (2016). Beneficence and procreation. Philosophical Studies, 173, 321-336.

Guadalupe, M., \& Salvatore, J. (2017). 'Her Opponent', documentary theatre re-creation of the USA 2016 presidential debates with genders swapped.

Harding, K. (2016). Reasons why Hillary Clinton has earned my vote. https://kateharding.net/2016/02/09/ reasons-why-hillary-clinton-has-earned-my-vote/.

Heyd, D. (2009). The intractability of the nonidentity problem. In M. A. Roberts \& D. T. Wasserman (Eds.), Harming future persons: Ethics, genetics and the nonidentity problem (pp. 3-25). London: Springer.

Hughes, C. (2004). Kripke. Oxford: Oxford University Press.

Jenny, M. (2018). Counterpossibles in science: The case of relative computability. Noûs, 52, 530-560.

Jamieson, A. (2017). If Trump were a woman: Play swaps presidential candidates' genders. The Guardian, www.theguardian.com/us-news/2017/jan/29/clintontrump-gender-swap-play-her-opponent.

Janssen-Lauret, F. (2016). Committing to an individual: Ontological commitment, reference, and epistemology. Synthese, 193(2), 583-604.

Janssen-Lauret, F. (2018). Logical form, the first person, and naturalism: The case against physicalist imperialism. In Scientific imperialism: Exploring the boundaries of interdisciplinarity (ed. M. Fernández Pinto, U. Mäki, A. Walsh). Routledge, pp. 237-253.

Janssen-Lauret, F., \& MacBride, F. (2020a). Lewis's global descriptivism and reference magnetism. Australasian Journal of Philosophy, 98(1), 192-198.

Janssen-Lauret, F., \& MacBride F. (2020b). W.V. Quine and David Lewis: Structural (epistemological) humility. In Quine: structure and ontology (ed. F. Janssen-Lauret), Oxford University Press, pp. $27-$ 55.

Johnston, M. (2011). On a neglected epistemic virtue. Philosophical Issues, 21, 165-218.

Korman, D. (2005). Law necessitarianism and the importance of being intuitive. Philosophical Quarterly, $55,649-657$.

Kripke, S. (1971). Identity and Necessity. In M.K. Munitz (ed.) Identity and Individuation. New York University Press, 1971, pp. 135-164. Reprinted in Kripke's Philosophical Troubles. Oxford University Press, 2011, pp. 1-26. 
Kripke, S. (1980). Naming and Necessity. Oxford: Blackwell.

Lewis, D. (1973). Counterfactuals. Oxford: Blackwell.

Lewis, D. (1986). On the plurality of worlds. Oxford: Blackwell.

MacBride, F., \& Janssen-Lauret, F. (2015). Meta-ontology, epistemology, and essence: On the empirical deduction of the categories. The Monist, 98(3), 290-302.

Maung, H. H. (2020). Epistemic possibility and the necessity of origin. Metaphilosophy, 51, 685-701.

Quine, W. V. (1960). Word and object. Cambridge, MA: MIT Press.

Quine, W. V. (1976) [1972]. Vagaries of Definition. In Ways of Paradox. Harvard University Press.

Robertson, T. (1998). Possibilities and the arguments for origin essentialism. Mind, 107, 729-749.

Ridley, J. (2019). King Alexander. Times Literary Supplement, https://www.the-tls.co.uk/articles/kingalexander/.

Rohrbaugh, G., \& deRosset, L. (2004). A new route to the necessity of origin. Mind, 113, 705-772.

Roth, C., Ferbert, A., Huegens-Penzel, M., Siekmann, R., \& Freilinger, T. (2018). Multimodal imaging findings during severe attacks of familial hemiplegic migraine type 2. Journal of Neurological Science, 392, 22-27.

Salmon, N. (1979). How not to derive essentialism from the theory of reference. Journal of Philosophy, 76, $703-725$.

Savali, K. W. (2016). Black feminists don't owe Hillary Clinton their support. www.theroot.com/blackfeminists-don-t-owe-hillary-clinton-their-support-1790854103.

Savulescu, J. (2002). Deaf Lesbians, Designer Disability and the Future of Medicine. British Medical Journal, 325, 771-773.

Schaefer, G. O., \& Labude, M. (2017). Genetic affinity and the right to three-parent IVF. Journal of Assisted Reproduction and Genetics, 34, 1577-1580.

Sidelle, A. (2010). Modality and objects. Philosophical Quarterly, 60, 109-125.

Smajdor, A. (2014). How useful is the concept of the harm threshold in reproductive ethics and law? Theoretical Medicine and Bioethics, 35, 321-336.

Strevens, M. (2012). Theoretical terms without analytic truths. Philosophical Studies, 160, 167-190.

Walker, M. (2008). Designer Babies and harm to supernumerary embryos. American Philosophical Quarterly, 45, 349-364.

Wrigley, A. (2012). Harm to future persons: Non-identity problems and counterpart solutions. Ethical Theory and Moral Practice, 15, 175-190.

Williams, N. (2013). Possible persons and the problem of prenatal harm. Journal of Ethics, 17, 355-385.

Williams, N., \& Harris, J. (2014). What is the harm in harmful conception? On threshold harms in nonidentity cases. Theoretical Medicine and Bioethics, 35, 337-351.

Williamson, T. (2007). The philosophy of philosophy. Oxford: Oxford University Press.

Wootton, D. (2019). Dolly Parton Says She's Not Gay and Slams 'Gossips' Who Claim Her Best Friend Is Actually Her Secret Girlfriend. The Sun, https://www.thesun.co.uk/tvandshowbiz/8455529/dollyparton-sexuality-rumours-secret-girlfriend/.

Publisher's Note Springer Nature remains neutral with regard to jurisdictional claims in published maps and institutional affiliations. 